\title{
Views of struggling students on instruction incorporating multiple strategies in Algebra I: An exploratory study
}

\section{Citation}

Lynch, K., \& Star, J.R. 2013. Views of struggling students on instruction incorporating multiple strategies in Algebra I: An exploratory study. Journal for Research in Mathematics Education.

\section{Permanent link}

http://nrs.harvard.edu/urn-3:HUL.InstRepos:10989382

\section{Terms of Use}

This article was downloaded from Harvard University's DASH repository, and is made available under the terms and conditions applicable to Open Access Policy Articles, as set forth at http:// nrs.harvard.edu/urn-3:HUL.InstRepos:dash.current.terms-of-use\#OAP

\section{Share Your Story}

The Harvard community has made this article openly available.

Please share how this access benefits you. Submit a story.

\section{Accessibility}


Running head(s):

Struggling Students’ Views of Multiple Strategies

Kathleen Lynch and Jon R. Star

\title{
Views of Struggling Students on Instruction Incorporating Multiple Strategies in Algebra I: An Exploratory Study
}

\author{
Kathleen Lynch and Jon R. Star \\ Harvard Graduate School of Education
}

Thanks to Courtney Pollack, Nataliia Perova, Kristie Newton, Bethany Rittle-Johnson, Christine Size, and Erin O'Connell for their assistance in data collection and analysis. This research is supported by a grant to the second author from the National Science Foundation (DRL0814571).

\begin{abstract}
Although policy documents promote teaching students multiple strategies for solving mathematics problems, some practitioners and researchers argue that struggling learners will be confused and overwhelmed by this instructional practice. In the current exploratory study, we explore how six struggling students viewed the practice of learning multiple strategies at the end of a yearlong algebra course that emphasized this practice. Interviews with these students indicated that they preferred instruction with multiple strategies to their regular instruction, often
\end{abstract}


noting that it reduced their confusion. We discuss directions for future research that emerged from this work.

Key words: Algebra and algebraic thinking, High school education, Middle school education, Multiple strategies

Recently, calls for “algebra for all” have pressured school districts to enroll students of all learning backgrounds in Algebra I, often as early as the seventh or eighth grade (Kilpatrick, 2009). However, it is also clear that students with weaker preparation frequently struggle in algebra classrooms (Steele \& Steele, 2003). As more students of diverse learning backgrounds enter Algebra I classrooms, the question of how to most effectively teach struggling algebra students has become increasingly important (Stein, Kaufman, Sherman, \& Hillen, 2011). One promising instructional approach that has the potential to improve struggling students' learning of algebra is the practice of comparing and discussing multiple solution strategies for mathematics problems. There is increasing evidence that this practice benefits students’ learning (e.g., Star \& Rittle-Johnson, 2008). It is also recommended in many recent policy reports in the United States (National Council of Teachers of Mathematics, 2006; National Research Council, 2001; Woodward et al., 2012), including the Common Core State Standards (National Governors Association Center for Best Practices \& Council of Chief State School Officers, 2010).

Despite apparent professional consensus, debate continues about whether instruction with multiple strategies is beneficial to all students or only to high-achieving students. These doubts 
come primarily from the practitioner community, but they also have some support from

researchers. For example, Silver, Ghousseini, Gosen, Charlambous, and Strawhun (2005) found that many teachers believed exploring multiple strategies would be feasible only with highability students. In addition, some researchers in special education advocate the presentation of a limited range of solution strategies (Montague, 1992; Scheuermann, Deshler, \& Schumaker, 2009), perhaps due to a perception that the cognitive load of a multiple-strategies approach may overwhelm struggling students (e.g., Baxter, Woodward, \& Olson, 2001; Baxter, Woodward, Voorhies, \& Wong, 2002). Baxter, Woodward, and Olson (2001) noted that some researchers in special education

view the discussion of alternative strategies and invented algorithms, a common approach in reform-based mathematics instruction, as problematic for low achievers because they believe multiple approaches to solving problems or even computing can only lead to confusion. These researchers see one simple set of rules as the best approach to teaching these students. (p. 530)

In this exploratory study, we consider the potential impact of instruction emphasizing multiple strategies. The current findings emerged from a pilot study in which a small group of Algebra I teachers implemented new, researcher-developed Algebra I curriculum materials that emphasized the comparison of multiple strategies. In this brief report, we describe our approach and highlight one element from our pilot work, the reactions of struggling students, ${ }^{1}$ that

\footnotetext{
${ }^{1}$ Note that we do not consider the label "struggling” (as in struggling students) to be merely another way to refer to students with learning disabilities. Both the mathematics education and special education literatures point out that some (but not all) students with learning disabilities struggle in mathematics, and some (but not all) students who struggle in mathematics have learning disabilities. However, there is a great deal of research within the field of special education on how to improve learning disabled students' performance in mathematics, and this
} 
suggests to us the need for a closer look at struggling algebra learners' experiences with multiple strategies in future research.

There is not unanimity in the field about what it means to teach mathematics with multiple strategies (Lynch \& Star, in press). In particular, instruction incorporating multiple strategies may include the following four implementation features. First, the problems used are often non-routine (i.e., problems where an algorithm may not exist). Second, students generate or invent their own solutions to the non-routine problems. Third, students have an opportunity to compare and contrast the multiple strategies, which may often involve the use of multiple representations such as symbols, tables, and graphs. And fourth, students and the teacher engage in a whole class synthesis discussion around the multiple strategies. Similarly, the incorporation of multiple strategies can have at least two instructional goals. First, through discussion of multiple strategies, students will develop understanding of underlying and important mathematical concepts, the ability to connect between and among different representations, and the rationale behind common algorithms. And second, students will know, are held accountable for, and are expected to subsequently use the discussed multiple strategies in future problem solving. These four features of multiple-strategy instruction, along with the two types of instructional goals, emerged from research around the learning and teaching of mathematics in elementary school, particularly the work of the Cognitively Guided Instruction (CGI) project (e.g. Carpenter, Franke, Jacobs, Fennema, \& Empson, 1998) combined with an emphasis on the use of multiple representations in algebra (e.g., Brenner et al., 1997; Star \& Rittle-Johnson, 2009b).

literature is very informative in our desire to learn more about how to assist struggling students in mathematics. 
Although we adopt the label multiple-strategy instruction in the present work, it is important to note that our approach does not incorporate all four implementation features describe above. In particular, instead of having students present and discuss their own invented solutions to non-routine problems, the focus of our curriculum materials was to allow students to present and discuss already-worked pairs of routine problems, which were presented side-by-side to facilitate comparison and discussion of multiple contrasting cases. This approach has been used successfully in several prior studies (e.g., Rittle-Johnson \& Star, 2007; Star \& RittleJohnson, 2009a). Despite the fact that we do not incorporate two implementation features that some may consider typical or even central to multiple-strategies instruction (student generation of strategies and use of non-routine problems), we feel justified in using the phrase to describe our approach for three reasons. First, it is not unusual for teachers to introduce strategies that were not generated by students into a multiple-strategies discussion, such as when a teacher illustrates an alternative strategy with the introduction, "A student from another class solved the problem this way—what do you think of this approach?” Second, despite our use of routine problems, the goals of our curriculum materials are well-aligned with both of the instructional goals noted above. And finally, those concerned with the appropriateness of multiple-strategy instruction indicate that it is the comparison of, discussion of, and expectation of subsequent use of multiple strategies that may overwhelm low achieving students (e.g., Baxter, Woodward, \& Olson, 2001)—rather than the invention of alternative strategies or the specific use of nonroutine problems.

\section{Method}


The curricular context for the present study is a set of researcher-designed instructional materials that infuse multiple strategies into a yearlong Algebra I course. The materials feature the characters Alex and Morgan, who solve problems using multiple strategies. The curriculum materials utilized in the current intervention focused on the specific practice of comparing multiple strategies via students' discussion of worked examples. More information about the curriculum materials can be found at http://gseacademic.harvard.edu/contrastingcases (see also Rittle-Johnson \& Star, 2011).

Figures 1-3 show sample pages from our curriculum. In some example pairs (Figures 1 and 2), Alex and Morgan are solving the same problem but in two different ways. In some instances, the instructional goal of this type of comparison is for students to see and understand alternative ways of solving routine problems, as in Figure 1, where Alex and Morgan use two mathematically equivalent but (to students) very different strategies. In other instances, the goal is for students to understand conceptually why a common strategy works or why a typical error occurs. For example, in the pair of worked examples shown in Figure 2, where Alex and Morgan have different approaches for simplifying $\left(6^{2}\right)\left(5^{2}\right)$, the comparison of Alex's and Morgan's ways is intended to support a discussion that conceptually unpacks what Morgan did and why it works. In other example pairs, Alex and Morgan solve two different problems but in similar ways. For example, in Figure 3, Alex graphed the equation $y=3 x$ and Morgan graphed the equation $y=3^{x}$, with the goal of understanding how and why these functions, whose symbolic representation looks quite similar, result in tables and graphs that have very important differences. The 141 example pairs that were included in the complete curriculum covered the entire range of typical Algebra I content. 
Which is better?

\section{Alex and Morgan were asked to solve $\frac{t}{3}-1=12$}

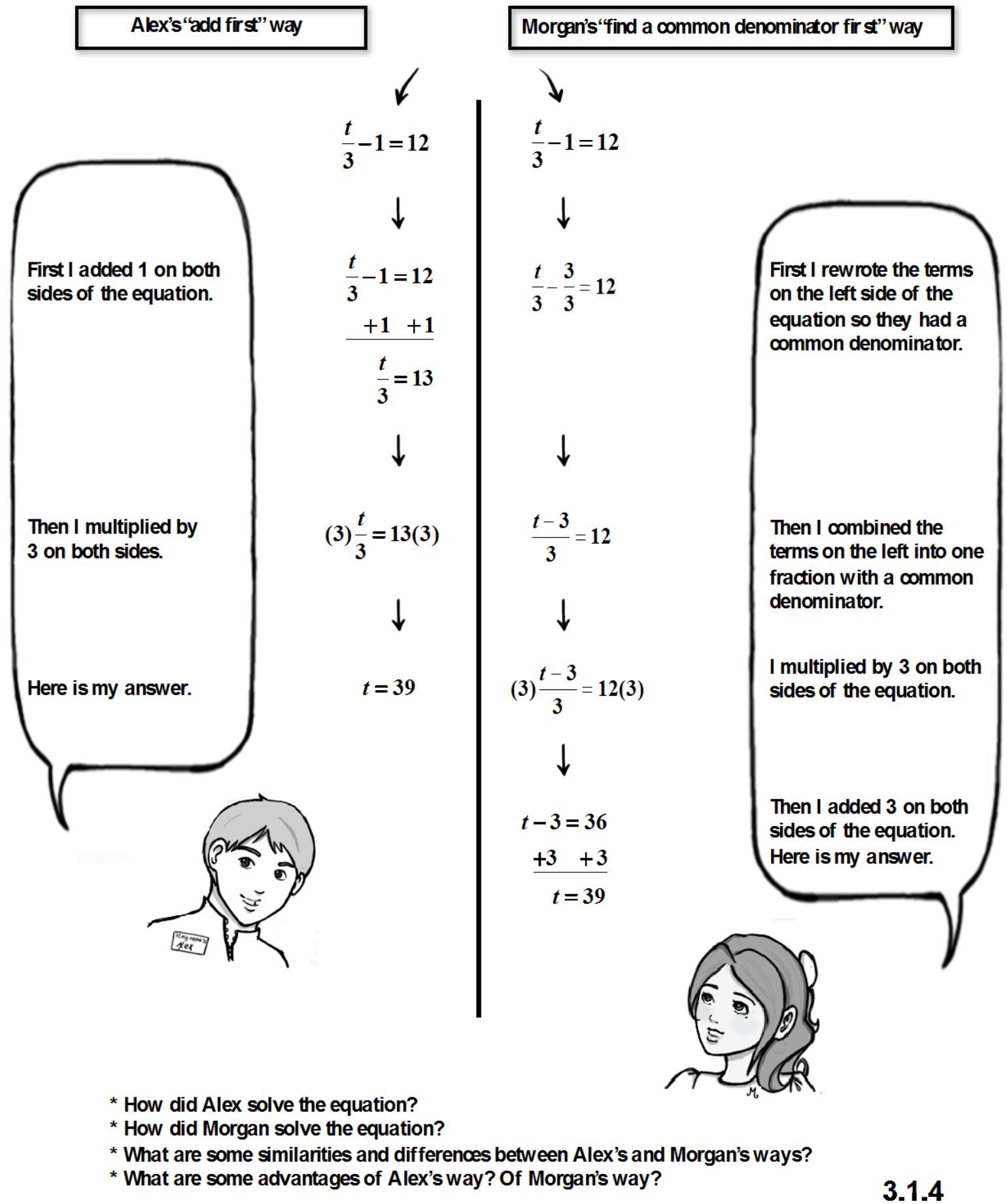

Figure 1. Example of a Which-is-better? worked example pair. 
Why does it work?

Alex and Morgan were asked to simplify $6^{2} \cdot 5^{2}$

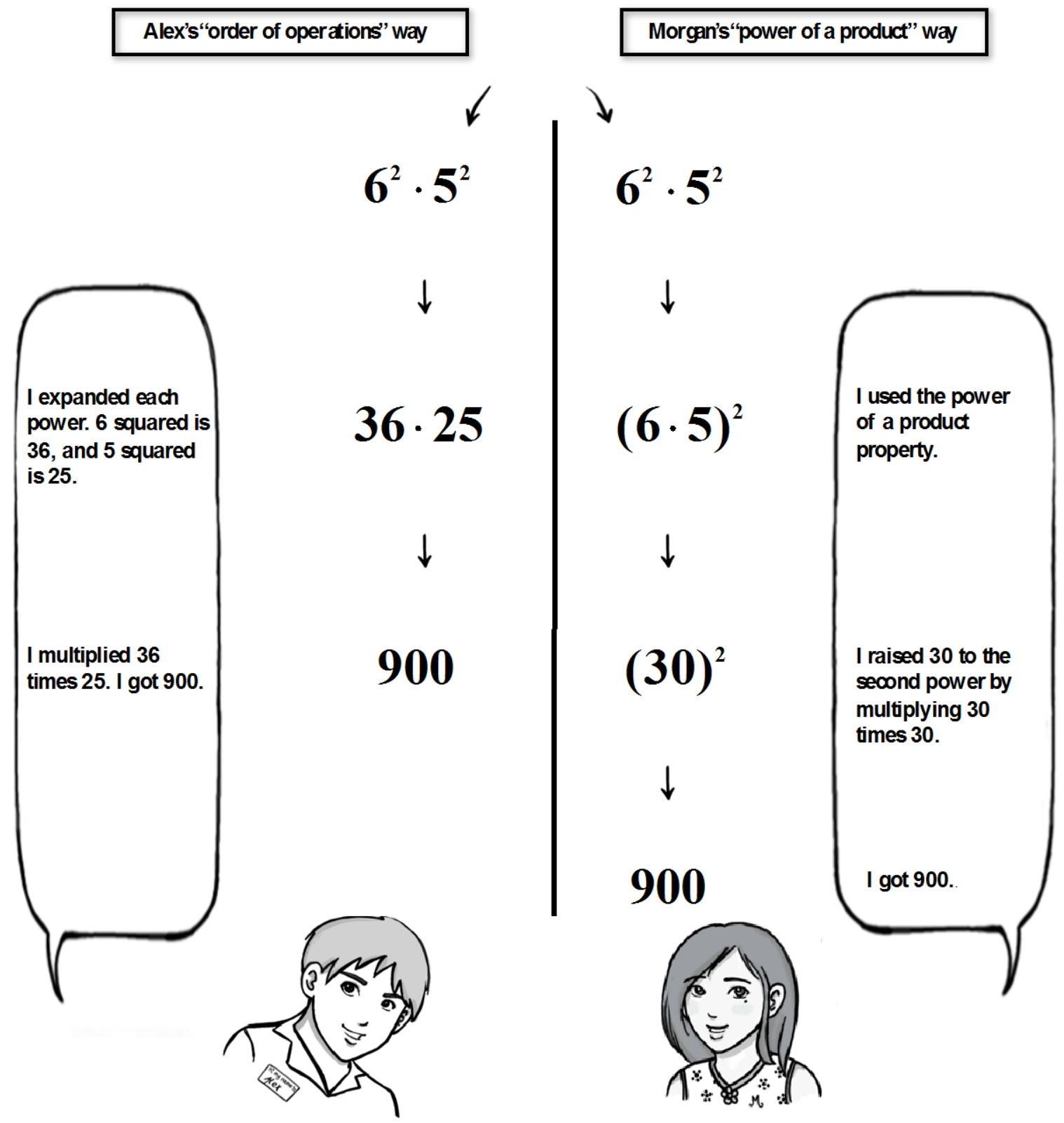

${ }^{*}$ How did Alex simplify the expression?

${ }^{*}$ How did Morgan simplify the expression?

* What are some similarities and differences between Alex's and Morgan's ways?

* Does Morgan's way always work? Why or why not?

9.4.1

Figure 2. Example of a Why-does-it-work? worked example pair. 
How do they differ?

Alex was asked to graph the equation $y=3 x$,

and Morgan was asked to graph the equation $y=3^{x}$.

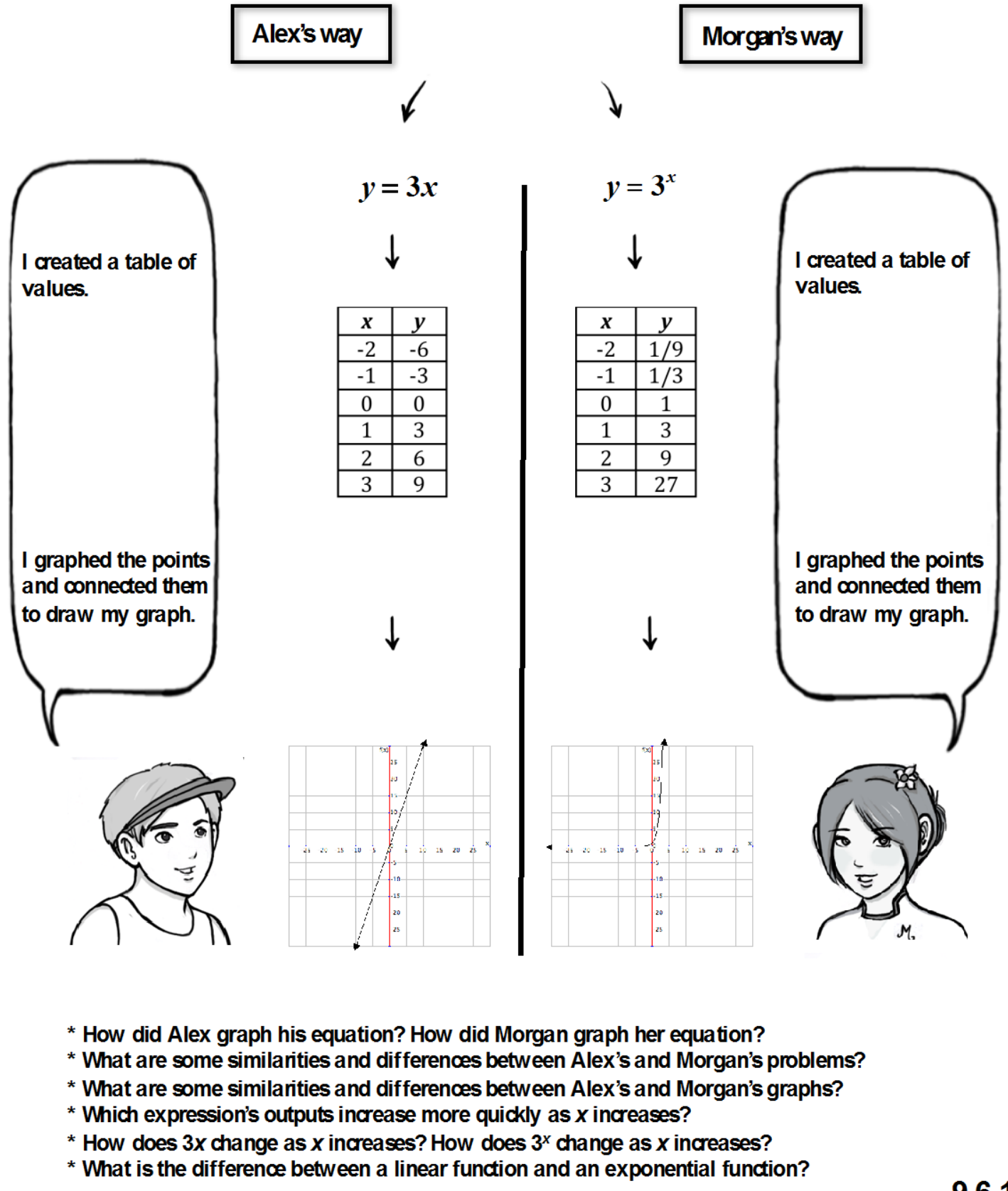

9.6 .1

Figure 3. Example of a How-do-they-differ? worked example pair. 
We developed a structured implementation model to accompany the written curriculum materials that consisted of three class discussion phases-Understand, Compare, and Make Connections. For each pair of worked examples, we provided reflection prompts for each phase. In the Understand phase, prompts such as, "How did Morgan solve the equation?” were intended to establish student comprehension of each individual strategy. In the Compare phase, prompts such as, "What are some similarities and differences between Alex’s and Morgan's ways?" were intended to guide students to compare the two strategies. The Understand and Compare phases were intended to prepare students for the final phase, Make Connections, in which prompts varied by the pair of worked examples and were intended to focus students' discussion on the instructional goal of the comparison. Although the worked examples that students compared were routine and frequently involved symbolic solution methods, the Make Connections phase was centrally concerned with understanding key algebraic principles. For example, in Figure 1, the discussion is launched through the questions that appear at the bottom of the page, with the expectation that the teacher will use students' answers to these questions to encourage consideration of why Alex's and Morgan's strategies work and what mathematical principles are brought to bear in each method. Similarly, in Figure 2, the Make Connections phase is focused on conceptually unpacking Morgan’s familiar strategy. Finally, in Figure 3, teachers were encouraged to push students toward understanding (via graphs, tables, and symbols) how and why linear and exponential functions differ. In this exploratory study, teachers were given flexibility in determining implementation details such as which examples to utilize in a class 
period and how much time to dedicate to each phase. For a more detailed discussion of the implementation model, see Rittle-Johnson and Star (2011).

The study was conducted in a large city in New England and its environs. Twelve middle and high school Algebra I teachers volunteered to participate in a weeklong institute on algebra teaching methods, where they were introduced to the curriculum materials as well as the structured implementation model described above. Teachers subsequently piloted the instructional materials during a year-long Algebra I course.

At the end of the Algebra I course (late May), teachers were instructed to select interviewees who had a wide range of attitudes and experiences with respect to the researcherdesigned intervention materials—some positive and some negative. The 30-minute interviews were semi-structured, exploring students' experiences in the Algebra I course, particularly with multiple strategies. See http://gseacademic.harvard.edu/contrastingcases/ for the interview protocol.

In total, we interviewed 23 students from ten schools. Of these 23 students, six scored in the "low" band of a standardized algebra readiness test administered at the beginning of the year, indicating that the students were unprepared for Algebra I and at an increased risk of subsequent low performance in the course. We targeted these six students' interviews for analysis because of our interest in the experiences of struggling students. Keisha (9th percentile on the pre-test) was in the eighth grade, while Mark (25th percentile), Gina (22nd percentile), Jordan (15th percentile), Isabel (1st percentile), and Nicole (1st percentile) were in the ninth grade.

Analysis of the interviews was conducted collaboratively, with multiple researchers engaging in coding and discussions (e.g., Lincoln \& Guba, 1985). While interviews touched on a range of topics, in this brief report we focus on students' perceptions of the advantages and 
disadvantages of learning with multiple strategies. We examined each student's complete interview for any references to advantages or disadvantages of learning with multiple strategies, both in questions that specifically asked for perceptions of advantages and disadvantages as well as in all other sections of the interview. The unit of analysis was the conversational turn, or statement bounded by a shift in speakers (also referred to by some researchers as a move or utterance), which could be a statement, a question, or an answer (Johnstone, 2002). After developing initial categories relating to advantages and disadvantages, we re-examined the interviews for evidence that might challenge our categories, constantly comparing identified codes with the original data. We resolved all disagreements through discussion until we reached consensus.

\section{Results}

\section{General Reactions to Instruction Using Multiple Strategies}

Students generally appeared to find the emphasis on more than one way to solve an algebraic problem relatively novel; five of the six noted that their previous teachers had infrequently or never emphasized this practice. To assess students’ general reactions, interviewers asked students what they thought about the focus on learning more than one way to solve problems. All of the students described multiple strategies as an improvement over "business as usual.” Several students stated that they enjoyed the multiple-strategy focus $(N=5)$ and that learning multiple strategies had improved their understanding and alleviated their past difficulties $(N=4)$, improved their problem solving success rate $(N=2)$, improved their attitudes toward mathematics $(N=1)$, and was thought-provoking $(N=1)$. 


\section{Perceived Advantages}

The most commonly cited advantage for multiple strategies, cited by all six of the students, was an increased awareness of different methods. Mark, for example, commented, I thought it was better because it could like, open different ways of how to do the problems. So like one way could be the way that everybody else was doing, and it could be hard, but then with Alex and Morgan, you see a different way to do it, that could be easier.

A second advantage, described by four students, was helping students find a method that “worked for them.” Gina, for example, stated,

I liked the multiple different ways, because the way some teachers have showed me in the past ... they might've not worked for me as well. But then now because I’ve seen, like, a different way, I like, may possibly like another way better. And I'm a lot better at it. Three students described multiple strategies as “easier” than learning one way; in a typical comment, Jordan stated, Learning different ways of how to solve a problem was the best part. Because, there are some times where, there was only one way, I would have only learned one way, but then when you find a different way to do it, it’s so much easier to you.

While many students spoke of affective advantages, two students more explicitly noted reduced anxiety about mathematics. For example, Keisha noted,

I think it's great, because sometimes, people, they're doing these kinds of problems, and they don't understand how to do them, but then if you're shown another way, and you're shown to do it better, and it's just, it can take relief off of some people. And I know it did for me. 
In addition, students noted that multiple strategies could improve accuracy $(N=2)$, provide a "back-up” method $(N=1)$, facilitate checking answers $(N=1)$, and help differentiate correct approaches $(N=1)$. Isabel, who had also stated that the materials helped her to understand the steps to solve different equations, additionally alluded to the relative efficiency of the strategies of Alex and Morgan:

Yeah, it helps, because instead of just using one strategy that's like, the longest, sometimes you would see that Alex was using a shorter way, or Morgan did. So I sometimes would use both ways, to like, solving an equation. It was cool, because I got to use the shorter way, which was much faster.

\section{Perceived Disadvantages}

Compared with the advantages, students cited disadvantages less frequently. Four students stated that for them, there were no disadvantages to this approach. In a typical comment, Mark stated, “Nothing, really. I thought it was, like, I thought it was helpful.” Three students made some reference to the possibility of confusion at any point in the interviews. One student, Nicole, who stated that she had not experienced any disadvantages from learning with multiple strategies, mentioned that her teacher had employed specific techniques when introducing multiple strategies “so we're not confused," including instructing the class to first look over Alex and Morgan’s solutions and then to read Alex and Morgan’s narrations of their steps. Two students, Jordan and Keisha, referenced confusion as a possibility for them more directly. For example, Keisha noted that “The disadvantages would be the other problems confusing you, and you not knowing which one to use and if that one’s correct or not.” However, Keisha then 
commented that this had never happened to her, because she was able to identify methods she was successful with and discard others.

Overall, what stands out about these comments is that although the risk of confusion appears real, students described their worries about confusion more sporadically and less forcefully than they described their appreciation for multiple strategies. Indeed, all of the students in the current sample reported that there were more advantages than disadvantages to learning more than one way to solve a problem.

\section{Discussion}

Mathematics instruction using multiple strategies appeared to be a novel experience for the six struggling students in the current sample. Despite its novelty, these six struggling students had quite positive perceptions of learning with multiple strategies, a view that runs counter to the perceptions of teachers in prior studies (e.g., Silver, Ghousseini, Gosen, Charalmbous, \& Strawhun,2005) and those of some researchers (e.g., Baxter et al., 2002). Concerns about overwhelming struggling students were largely not substantiated among the students we interviewed. In fact, these six students cited the advantage of improved understanding and reduced anxiety repeatedly throughout the interviews. Also contrary to what might have been expected, these six struggling students cited relatively few disadvantages to learning multiple strategies and felt that the risk of confusion was relatively minor.

How can we explain this disconnect between some teachers’ concerns about multiple strategies for struggling students generally and these six struggling students’ own expressed enthusiasm for this practice after a year of engaging with it? While our current data do not address this question specifically, we speculate that perhaps some teachers' hesitation may be 
rooted in their own real prior experiences with attempting to present multiple strategies to struggling learners with unsuccessful results. In this context, we speculate that perhaps the specific structural components of the current intervention and its implementation may have contributed to its greater success in reaching these six struggling students—in other words, that the how of implementing multiple-strategies instruction mattered a great deal.

In particular, the current intervention was carefully designed to maximize the likelihood that students would reap the benefits of multiple strategies, while reducing the likelihood of overload. In particular, our approach incorporated the following components: (a) already worked examples, rather than student invention of multiple strategies; (b) carefully selected routine examples to be compared (such that the compared examples did not vary across too many dimensions, but rather were mostly similar, so that elements of differences could be easily identified); (c) engaging cartoon characters; (d) explicit, step-by-step presentation of worked examples in both words (via dialogue bubbles) and mathematics syntax; and (e) a structured implementation model that gave guidance to teachers on ways to compare, contrast, and discuss multiple strategies conceptually and procedurally without overloading students. Certainly teachers' concerns about overloading students are important and valid. Without careful consideration of how to teach with multiple strategies, including keen attention to both selection of examples to be compared and to presentation structure, students may indeed become confused. Our results suggest, however, that with these elements, even struggling students may benefit from this instructional approach.

The current study is exploratory in nature and has multiple limitations. First, we used a small convenience sample of volunteer teachers and as such their adherence to the curriculum developers' intended implementation model may have been unusually strong. Second, teachers 
selected students to be interviewed. Although teachers were instructed to select interviewees with a wide range of attitudes about the materials, we have no way to know whether this was indeed the case. Third, the students were aware that the interviewers were members of the research group that created the materials. As a result, one might speculate that the students might have wished to please the researchers and say only positive things about the curriculum. However, we suspect that such an effect was relatively minor; students appeared relatively uninhibited in their critiques of some elements of the intervention. Finally, our small sample clearly limits our ability to generalize the present findings.

\section{Conclusions and Future Research Directions}

Contrary to what might have been expected from the existing literature, the six struggling students in the current study described quite positive experiences from learning algebra with a multiple-strategies approach. We suggest that the current findings may present a form of existence proof of the conception that under ideal circumstances, and with carefully designed curriculum materials, struggling students can emerge from a yearlong algebra course infused with multiple strategies with quite positive views of this approach, preferring it to their regular instruction. Although the current findings are exploratory in nature and not argued to be representative of struggling algebra learners broadly, our results suggest it may be productive to revisit the question of whether and how struggling students should be exposed to multiple strategies. In particular, future studies could examine classrooms where teachers use a multiplestrategies approach to parse which elements of instruction and curriculum may best support struggling learners. In addition, future, larger studies should include student assessments of both procedural and conceptual algebra knowledge in order to evaluate the effectiveness of instruction 
with multiple strategies at a larger scale. In addition, future research should systematically measure teachers' fidelity of implementation in order to explore the critical consideration of whether the curriculum was taught consistently or modified across classrooms. An additional promising direction for future research is an extension of the current curriculum materials to include a broader array of problem types, including non-routine problems for which there is no defined or specific solution algorithm or pathway. Our efforts to explore these avenues for future research are currently underway.

Given the critical need to improve algebra instruction for this growing population, we hope that the current exploratory findings might prompt future research to explore struggling algebra students’ engagement with multiple strategies in greater depth.

\section{References}

Baxter, J., Woodward, J., \& Olson, D. (2001). Effects of reform-based mathematics instruction in five third-grade classrooms. Elementary School Journal, 101(5), 529-548. doi:10.1086/499686

Baxter, J., Woodward, J., Voorhies, J., \& Wong, J. (2002). We talk about it, but do they get it? Learning Disabilities Research \& Practice, 17(3), 173-185.

Brenner, M. E., Mayer, R. E., Moseley, B., Brar, T., Duran, R., Reed, B. S., \& Webb, D. (1997). Learning by understanding: The role of multiple representations in learning algebra. American Educational Research Journal, 34(4), 663-689.

Carpenter, T. P., Franke, M. L., Jacobs, V. R., Fennema, E., \& Empson, S. B. (1998). A longitudinal study of invention and understanding in children's multidigit addition and subtraction. Journal for Research in Mathematics Education, 29(1), 3-20. 
Lynch, K., \& Star, J.R. (in press). Teachers' views about multiple strategies in middle and high school mathematics: Perceived advantages, disadvantages, and reported instructional practices. Mathematical Thinking and Learning.

Johnstone, B. (2002). Discourse analysis (2nd ed.). Malden, MA: Blackwell.

Kilpatrick, J. (2009). Algebra is symbolic. In Swars, S. L., Stinson, D. W., \& Lemons-Smith, S. (Eds.). Proceedings of the 31st Annual Meeting of the North American Chapter of the International Group for the Psychology of Mathematics Education (Vol. \#5, pp. 11-21). Atlanta, GA: Georgia State University.

Lincoln, Y. S., \& Guba, E. G. (1985). Naturalistic inquiry. Beverly Hills, CA: Sage.

Montague, M. (1992). The effects of cognitive and metacognitive strategy instruction on the mathematical problem solving of middle school students with learning disabilities, Journal of Learning Disabilities, 25(4), 230-248.

National Council of Teachers of Mathematics. (2006). Curriculum focal points for prekindergarten through grade 8 mathematics. Reston, VA: Author.

National Governors Association Center for Best Practices \& Council of Chief State School Officers. (2010). Common core state standards for mathematics. Retrieved from http://www.corestandards.org/assets/CCSSI_Math\%20Standards.pdf

National Research Council. (2001). Adding it up: Helping children learn mathematics. Washington, DC: National Academy Press.

Rittle-Johnson, B. \& Star, J. (2007). Does comparing solution methods facilitate conceptual and procedural knowledge? An experimental study on learning to solve equations. Journal of Educational Psychology, 99(3), 561-574. 
Rittle-Johnson, B., \& Star, J. R. (2011). The power of comparison in learning and instruction: Learning outcomes supported by different types of comparisons. In J. P. Mestre \& B. H. Ross (Eds.), Psychology of Learning and Motivation: Cognition in Education (Vol. 55, pp. 199-222). Waltham, MA: Elsevier. doi:10.1016/B978-0-12-387691-1.00007-7.

Scheuermann, A. M., Deshler, D. D., \& Schumaker, J. B. (2009). The effects of the explicit inquiry routine on the performance of students with learning disabilities on one-variable equations. Learning Disability Quarterly, 32(2), 103-120.

Silver, E. A., Ghousseini, H., Gosen, D., Charalambous, C., \& Strawhun, B. (2005). Moving from rhetoric to praxis: Issues faced by teachers in having students consider multiple solutions for problems in the mathematics classroom. Journal of Mathematical Behavior, 24, 287-301.

Star, J. R. \& Rittle-Johnson, B. (2008). Flexibility in problem solving: The case of equation solving. Learning and Instruction, 18, 565-579.

Star, J. R. \& Rittle-Johnson, B. (2009a). It pays to compare: An experimental study on computational estimation. Journal of Experimental Child Psychology, 102(4), 408-426. doi: 10.1016/j.jecp.2008.11.004

Star, J.R., \& Rittle-Johnson, B. (2009b). Making algebra work: Instructional strategies that deepen student understanding, within and between representations. ERS Spectrum, 27(2), $11-18$.

Steele, M. M., \& Steele, J. W. (2003). Teaching algebra to students with learning disabilities. Mathematics Teacher, 96(9), 622-624.

Stein, M. K., Kaufman, J. H., Sherman, M. \& Hillen, A. (2011). Algebra: A challenge at the crossroads of policy and practice. Review of Educational Research, 81(4), 453-492. 
Woodward, J., Beckmann, S., Driscoll, M., Franke, M. L., Herzig, P., Jitendra, A. K., ... Ogbuehi, P. (2012). Improving mathematical problem solving in grades 4 to 8: A practice guide (NCEE 2012-4055). Washington, D.C.: National Center for Education Evaluation and Regional Assistance, Institute of Education Sciences, U.S. Department of Education. Retrieved from http://ies.ed.gov/ncee/wwc/pdf/practice_guides/mps_pg 052212.pdf

\section{Authors}

Kathleen Lynch, Harvard Graduate School of Education, Harvard University, 211 Longfellow Hall, 13 Appian Way, Cambridge, MA, 02138; kathleen_lynch@mail.harvard.edu

Jon R. Star, Harvard Graduate School of Education, Harvard University, 442 Gutman Library, 6 Appian Way, Cambridge, MA, 02138; jon_star@harvard.edu

Accepted April 4, 2013 